\title{
AVALIAÇÃO QUANTITATIVA DE RISCO MICROBIOLÓGICO À SAÚDE HUMANA ASSOCIADO AO REÚSO DE ESGOTO DOMÉSTICO TRATADO POR SOLUÇÕES BASEADAS NA NATUREZA
}

\author{
QUANTITATIVE MICROBIOLOGICAL RISK ASSESSMENT TO HUMAN HEALTH ASSOCIATED \\ WITH THE REUSE OF DOMESTIC WASTEWATER TREATED BY NATURE-BASED \\ SOLUTIONS
}

Vinícius Bispo dos Santos ${ }^{a}$, Paula Loureiro Paulo ${ }^{b}$, Priscila Sabioni Cavalheria, Priscila de Morais Limac$^{c}$, Fernando Jorge Corrêa Magalhães Filhoab

a Universidade Católica Dom Bosco, ${ }^{b}$ Universidade Federal do Mato Grosso do Sul, ' Swedish University of Agricultural Sciences

viniciusbispods@gmail.com,ppaulo.ufms@gmail.com,priscilasabioni@hotmail.com, pri.lima.91@gmail.com, fernandoicmf@hotmail.com

Submissão: 28 de fevereiro de 2021 Aceitação: 1 de julho de 2021

\section{Resumo}

Diferentes alternativas para o reúso de esgoto doméstico tratado têm sido estudadas de forma extensiva, buscando principalmente tecnologias de tratamento com melhor desempenho na remoção de patógenos. As soluções baseadas na natureza têm se destacado pela sua capacidade de remoção de poluentes, com processos ecológicos, simples e robustos, entretanto, necessitam de maiores estudos relacionados aos riscos que envolvem o reúso de água a partir do esgoto tratado. Sendo assim, o objetivo deste estudo foi quantificar os riscos à saúde humana no reúso de esgoto doméstico tratado para fins agrícolas, por meio de uma Avaliação Quantitativa de Risco Microbiológico (AQRM). Foram avaliados três processos de tratamento: Tanque séptico (TS) + Wetland Construído de Fluxo Vertical (WC-FV), TS + Lagoas de Estabilização e TS + Lagoas de Estabilização + WC-FV, utilizando E. coli como indicador, e Campylobacter, Cryptosporidium e Rotavirus como patógenos de referência. Foi definido como potencial risco um cenário crítico, qual seja, o consumo de culturas cruas de alface, cebola e pepino, assim como os riscos oferecidos na irrigação por aqueles que trabalham nos campos irrigados e podem ingerir involuntariamente quantidades (partículas) de solo contaminado (contato da mão na boca, sem equipamento de proteção individual, como luvas), a partir de três subcenários: a agricultura mecanizada (AAM), agricultura com mão de obra intensiva (AMI) e agricultura com mão de obra reduzida (AMR). Os resultados demonstraram que os arranjos TS + WC-FV, TS + Lagoas de Estabilização e TS + Lagoas de Estabilização + WC-FV atenderiam o valor estabelecido pela Organização Mundial da Saúde (OMS) de 10-6 DALYs pppy (anos de vida ajustados por incapacidade, por pessoa por ano) nas culturas de pepino e cebola, e, no subcenário de AAM, somente atenderia o cultivo de alface. Caso o valor de DALYs pppy fosse menos restritivo (10-4), já que a incidência diarreica é superior em países em desenvolvimento $\left(10^{-2}\right)$, atenderia para o consumo de todas as culturas e todos os subcenários.

Palavras-chave: reúso agrícola; área úmida construída; lagoa de estabilização; rotavírus; cryptosporidium.

\section{Abstract}

The alternatives for reuse of treated domestic sewage have been studied extensively, mainly seeking treatment technologies with better performance in the pathogen'sremoval. Among these technologies, nature-based solutions have stood out for their ability to remove pollutants, in addition to their processes being natural and robust, these systems need further studies related to the risks involvedin the waterreuse from the treated effluent. Therefore, this study aimed to quantify the risks to human health in the application 
of treated domestic effluent in agriculture, through a Quantitative Microbiological Risk Assessment (QMRA). Three treatment processes were evaluated: Septic tank (ST) + Vertical flow constructed wetlands (VF-CW), ST + Stabilization Ponds, and ST + Stabilization Ponds + VF-CW, using E. coli as a pathogen indicator, and Campylobacter, Cryptosporidium and Rotavirus as reference pathogens. Potential risk was defined as the consumption of raw lettuce, onion and cucumber crops, as well as the risks offered by irrigation by those who work in the irrigated fields and who may involuntarily ingest quantities of contaminated soil (hand-to-mouth contact, without individual protective equipment, such as gloves) from three sub-scenarios: mechanized agriculture (AAM), labor-intensive agriculture (AMI) and reduced-labor agriculture (AMR). The results showed that the ST + VF-CW, ST + Stabilization Ponds, and ST + Stabilization Ponds + VF-CW arrangements would meet the value established by the World Health Organization (WHO) of 10-6 DALYs pppy (years of disability adjusted lives, per person per year) in cucumber and onion crops, and in the AAM sub-scenario, but would only serve lettuce cultivation. If the value of DALYs pppy was less restrictive $\left(10^{-4}\right)$, since the diarrheal incidence is higher in developing countries $\left(10^{-2}\right)$, it would be suitable for the consumption of all cultures and all sub-scenarios.

Keyword: agricultural reuse; constructed wetland; stabilization pond; rotavirus; cryptosporidium.

\section{INTRODUÇÃo}

O reúso de esgoto doméstico tratado vem tornando-se cada vez mais vantajoso para a operação das Estações de Tratamento de Esgoto (ETEs), o que propicia o conceito de economia circular, baseado na abordagem nexus (água, energia e alimento). Cerca de 330 bilhões de $\mathrm{m}^{3} \cdot \mathrm{ano}^{-1}$ de esgotos domésticos municipais são gerados globalmente, sendo teoricamente suficientes para irrigar e fertilizar milhões de hectares de plantações. No entanto, apenas uma pequena parte recebe tratamento, e a proporção que é reutilizada com segurança é significativamente menor do que o uso direto existente e menor do que a utilização indireta de esgoto doméstico não tratado, o que propicia riscos potenciais para a saúde (MATEOSAGASTA et al., 2015).

Uma solução proposta para amenizar a problemática é a utilização de ETEs descentralizadas, de forma a diminuir o aporte financeiro inicial de implantação ou, até mesmo, a utilização de soluções individuais de tratamento de esgoto. Dessa forma, tecnologias de tratamento naturais vêm ganhando atenção especial, devido ás suas facilidades de operação, robustez no tratamento e menores custos de implantação e operação. No território brasileiro, o tratamento natural com lagoas de estabilização já é consolidado, devido ao clima favorável e à disponibilidade de área. Dentre os arranjos mais utilizados, tem-se o maior número de unidades implantadas, cerca de 364 ETEs compostas por Lagoas Anaeróbias + Lagoas Facultativas e 203 ETEs usam Lagoas Facultativas (ANA, 2017).
Muitos estudos no Brasil estão buscando diferentes combinações de processos com ecotecnologias, principalmente com os wetlands construídos, com intuito de tornar os sistemas mais eficientes, com menores custos de implantação, operação e manutenção (ATALLA et al., 2020; BASSANI et al., 2021; DECEZARO et al., 2019; de OLIVEIRA et al., 2019; MAGALHÃES FILHO et al., 2018; MAZUCATO et al., 2020; SANTOS et al., 2020), embora ainda não apareçam com representatividade na matriz tecnológica brasileira. Os wetlands construídos (WC) são exemplos de tecnologias definidas como reatores que integram a interação entre água-planta-meio filtrante e que buscam replicar o sistema de depuração de águas realizado na natureza por meio de pântanos ou áreas alagadas (KADLEC; WALLACE, 2008).

Nesse sentido, para tornar a implantação de ETEs, que utilizem soluções baseadas na natureza, mais atrativa, com viabilidade financeira e que agregue valor para as mesmas, uma opção é investir no reúso para fins agrícolas. Entretanto, essa prática oferece alguns riscos, sendo a carga de patógenos a maior preocupação para o agronegócio, requerendo cada vez mais tratamentos avançados, o que pode inviabilizar a prática de reúso.

Em relação ao desempenho dessas tecnologias, é conhecido que uma eficiência típica de remoção em WC varia de 3 a 4 log de coliformes termotolerantes, enquanto as lagoas de estabilização (Lagoa Anaeróbia + Lagoa Facultativa + Lagoa de Maturação) removem 3 a 5 log de termotolerantes (considerando que Escherichia coli é $95 \%$ de coliformes totais), 
conforme von Sperling (2007). Ainda assim, essas remoções logarítmicas de patógenos propostas para essas soluções não atenderiam inteiramente 0 uso na agricultura, considerando que um esgoto doméstico tem de $10^{6}-10^{9} \mathrm{E}$. coli. $100 \mathrm{~mL}^{-1}$ (von SPERLING 1996; WHO, 2016b, 2006a). A Organização Mundial da Saúde (OMS) exige qualidade da água em $3 \log$ E. coli. $100 \mathrm{~mL}$ 1 para irrigação irrestrita em cultivos de raízes, 4 logs E. coli. $100 \mathrm{~mL}^{-1}$ para irrigação irrestrita em cultivos de folhas ou na irrigação restrita com agricultura de mão de obra intensiva e de alto contato, e 5 logs E. coli. $100 \mathrm{~mL}^{-1}$ para irrigação irrestrita em sistema por gotejamento e cultivos de porte alto ou na irrigação restrita com agricultura mecanizada (WHO, 2006a).

Estas restrições definem um nível globalmente aceitável de proteção à saúde, sendo baseadas no atendimento à carga de doença tolerável, determinada por anos de vida ajustados por incapacidade de vida (DALYs) por pessoa por ano (pppy), no valor de $10^{-6}$. Este valor de $10^{-6}$ DALYs pppy significa que uma cidade de um milhão de pessoas sofreria coletivamente a perda de um DALY por ano. A OMS aplicou esse nível de proteção à saúde em suas diretrizes de 2004 sobre a qualidade de água potável (WHO, 2004), e, desta forma, os riscos à saúde decorrentes do uso de água tratada de efluente doméstico na agricultura são os mesmos que os de consumir água potável (MARA, 2008). Sendo assim, são necessários mais estudos avaliando de forma quantitativa os riscos microbiológicos que a aplicação de esgoto doméstico tratado na agricultura, realmente, pode oferecer, inclusive levando em consideração as condições locais de acesso aos serviços de saneamento básico.

Para realização de uma Avaliação Quantitativa de Risco Microbiológico (AQRM) à saúde, a OMS estabelece cálculos probabilísticos, a partir de modelos de doseresposta em humanos, publicados para cada patógeno em específico, devido à sua variação de risco em infecção ou doença, sendo que nem todos os indivíduos infectados desenvolverão sintomas, desta forma, estimando probabilidades de doenças após a infecção. Os indicadores de contaminação fecal mais comumente utilizados são os coliformes totais, coliformes termotolerantes e a Escherichia coli (E. coli) que é o principal indicador. Para uma melhor definição dos riscos oferecidos, a WHO (2016a) estabelece três (3) patógenos de referência: Rotavirus (um vírus), Campylobacter (uma bactéria) e Cryptosporidium (um protozoário). Muitos estudos vêm definindo as estimativas de organismos patogênicos a partir de organismos indicadores, sendo recomendados e utilizados por diversos autores (BASTOS et al., 2008; MARA; SLEIGH, 2010; McBRIDE et al., 2013; ORAGUI et al., 1987; PAVIONE et al., 2013; TEUNIS et al., 2008). No entanto, esses estudos não são focados em soluções baseadas na natureza e, também, não consideram a realidade brasileira.

Sendo assim, o objetivo deste trabalho foi realizar uma AQRM à saúde humana, associada ao reúso de esgoto doméstico tratado por soluções baseadas na natureza, para fins agrícolas.

\section{MATERIAL E MÉTODOS}

Os sistemas de tratamento de esgoto doméstico avaliados (Figura 1) estão localizados no Centro de Tecnologia e Agronegócio (CeTeAgro), vinculados à Universidade Católica Dom Bosco (UCDB), em Campo Grande, Mato Grosso do Sul (latitude 20 23'17.77" S e longitude $54^{\circ} 36^{\prime} 26,10^{\prime \prime} \mathrm{W}$ ), os quais geram diariamente $38,4 \mathrm{~m}^{3}$ de esgoto doméstico.

\subsection{Descrição dos sistemas de tratamento}

A ETE do CeTeAgro contém um tanque séptico (TS) com dimensões internas úteis de 5,7 x 12,29 x 3,14 m, volume útil de $220 \mathrm{~m}^{3}$ e com tempo de detenção hidráulica (TDH) de 5,73 dias, e possui um sistema de lagoas de estabilização (lagoa anaeróbia, lagoa facultativa e lagoa de maturação). A lagoa anaeróbia (LA) possui um volume de 436,59 $\mathrm{m}^{3}$ e TDH de 11,36 dias; a lagoa facultativa (LF), um volume de $355,40 \mathrm{~m}^{3} \mathrm{e}$ TDH de 9,5 dias; e a lagoa de maturação, um volume de $243,25 \mathrm{~m}^{3}$ e TDH 6,35 dias. Os valores do TDH estão acima do que é preconizado pela literatura, normas e diretrizes técnicas, pois os sistemas foram projetados e operam há mais de 20 anos, quando se esperava um aumento considerável na vazão, fato que não ocorreu. Entretanto, os valores de remoção para Escherichia coli, sendo o parâmetro de interesse neste estudo, estão na faixa encontrada na literatura, ou seja, embora o TDH seja maior, isso não refletiu em um decaimento maior para esse indicador de patogenicidade.

Em seguida, têm-se dois Wetlands Construídos de Fluxo Vertical (WC-FV) em escala piloto, com área superficial de $710 \mathrm{~cm}^{2}$ e uma 
altura total de $80 \mathrm{~cm}$, possuindo um meio filtrante de $60 \mathrm{~cm}$ (areia), uma camada superficial livre de $5 \mathrm{~cm}$ para aplicação do efluente. De modo a evitar o transbordamento devido à possível colmatação, existe uma camada de cascalho fino de $5 \mathrm{~cm}$ na superfície para impedir erosão do meio filtrante, e uma camada de $5 \mathrm{~cm}$ de brita média $(4,8$ a $9,5 \mathrm{~mm}$ ) e $5 \mathrm{~cm}$ de brita grossa ( $25 \mathrm{a}$ $32 \mathrm{~mm}$ ) no fundo, operando em fluxo descendente. Um dos WC-FV é plantando com Heliconiarostrata (sendo assim denominado WC$\mathrm{FV} \mathrm{H}$ ) e recebe efluente pós tratamento no TS, enquanto o outro é plantado com Solanumly copersicum var. cerasiforme (denominado WC-FV $\mathrm{T})$, conhecida popularmente como "tomatecereja", e recebe efluente pós tratamento pelo TS e Lagoas de estabilização.

Figura 1. Delineamento representativo dos sistemas avaliados.

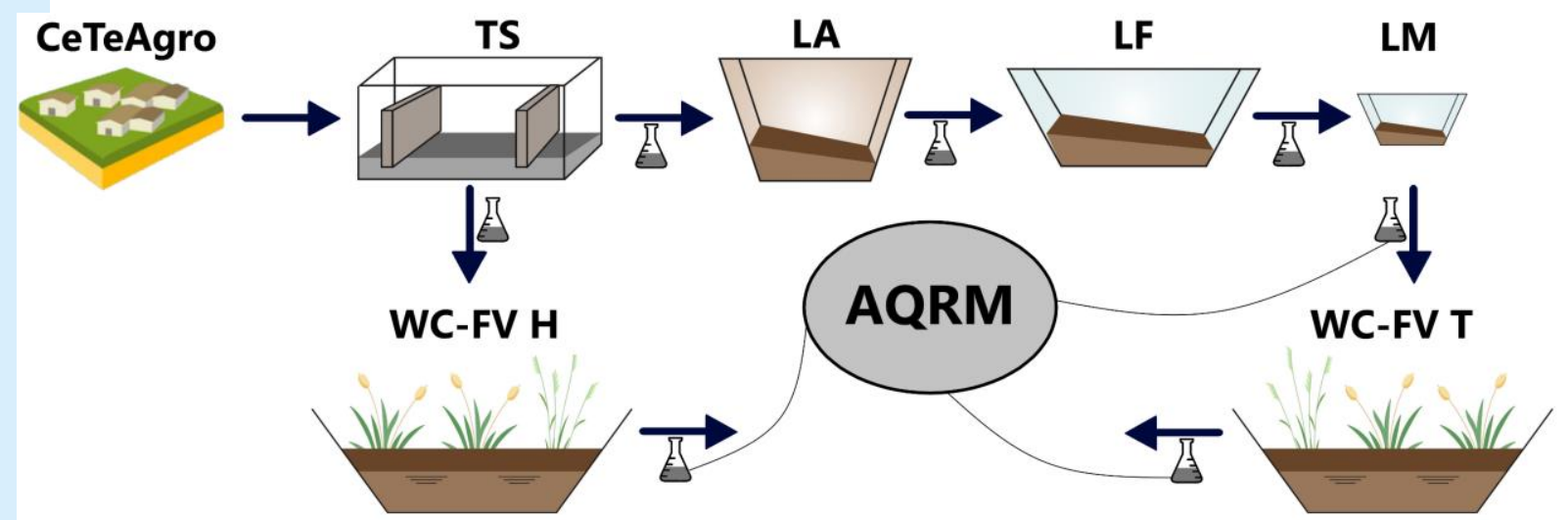

Sistemas: (A) TS + WC-FV H; (B) TS + LA + LF + LM; e (C) TS + LA + LF + LM + WC-FV T. TS - Tanque Séptico; LA - Lagoa Anaeróbia; LF - Lagoa Facultativa; LM - Lagoa de Maturação; WC-FVH - Wetland Construído de Fluxo Vertical Plantado com Helicônia; WC-FV T - Wetland Construído de Fluxo Vertical com Solanum lycopersicum var. cerasiforme.

Fonte: Elaborada pelos autores.

\subsection{Análise microbiológica}

O período de análise variou conforme o arranjo da seguinte forma:

- TS + WC-FV H: 40 amostragens durante os anos de 2017 e 2018;

- TS + LA + LF + LM: 273 amostragens durante os anos de 2010 a 2015; e

- TS + LA + LF + LM + WC-FV T: 33 amostragens durante $o$ ano de 2016.

As amostras coletadas na entrada e saída das unidades foram analisadas em triplicata, em que o microrganismo Escherichia coli (E. coli) foi analisado pelo método 9223B, de acordo com os "Métodos Padrões para Avaliação de Água e Esgoto" - Standard Methods for the Examination of Water and Wastewater (CARRANZO, 2012)

2.3. Avaliação quantitativa de risco microbiológico (AQRM)

A avaliação foi realizada utilizando $E$. coli como patógeno indicador e Campylobacter,
Cryptosporidium e Rotavirus como patógenos de referência. Como potencial risco, foram definidos o consumo das culturas cruas de alface, cebola e pepino, mas, também, os riscos oferecidos na irrigação por aqueles que trabalham nos campos irrigados e podem ingerir involuntariamente quantidades de solo contaminado, a partir de três subcenários: a agricultura mecanizada (AAM), agricultura com mão de obra intensiva (AMI) e agricultura com mão de obra reduzida (AMR).

As medidas quantitativas de risco podem ser quantificadas em métricas diferentes das informações coletadas durante as avaliações de exposição e efeitos à saúde, incluindo a probabilidade de infecção e de doença, número esperado de casos de doença e, também, como DALY (anos de vida ajustado por incapacidade), não devendo ser excedido $10^{-6}$. A escala de tempo do risco pode ser para uma única exposição, exposições independentes ou em anos (WHO, 2016b). Para efeitos da avaliação, foram definidas quatro etapas da estrutura AQRM, de forma a evidenciar os riscos na aplicação de água tratada de esgoto doméstico 
em cultivos, sendo elas:

1. Formulação de problemas;

2. Avaliação da exposição;

3. Avaliação dos efeitos na saúde; e

4. Caracterização da avaliação quantitativa de risco.

\subsubsection{Formulação do problema}

No cenário de aplicação de efluente doméstico tratado na agricultura, as atividades operacionais de produção de culturas alimentares e o consumo podem potencialmente expor 0 operador a patógenos microbianos, mas, também, o consumidor final. Portanto, foram estabelecidos dois cenários de irrigação, quais sejam, a irrigação restrita e a irrigação irrestrita, determinados pela qualidade do efluente, conforme demonstrado na Figura 2.

A irrigação por gotejamento (gota a gota) foi desconsiderada por se tratar de uma rega localizada que utiliza quantidade de água menor que as outras formas de irrigação, portanto, a exposição dos agricultores ao risco é substancialmente reduzida e resulta em uma menor contaminação das culturas.

Figura 2. Vias de exposição dos cenários de irrigação.

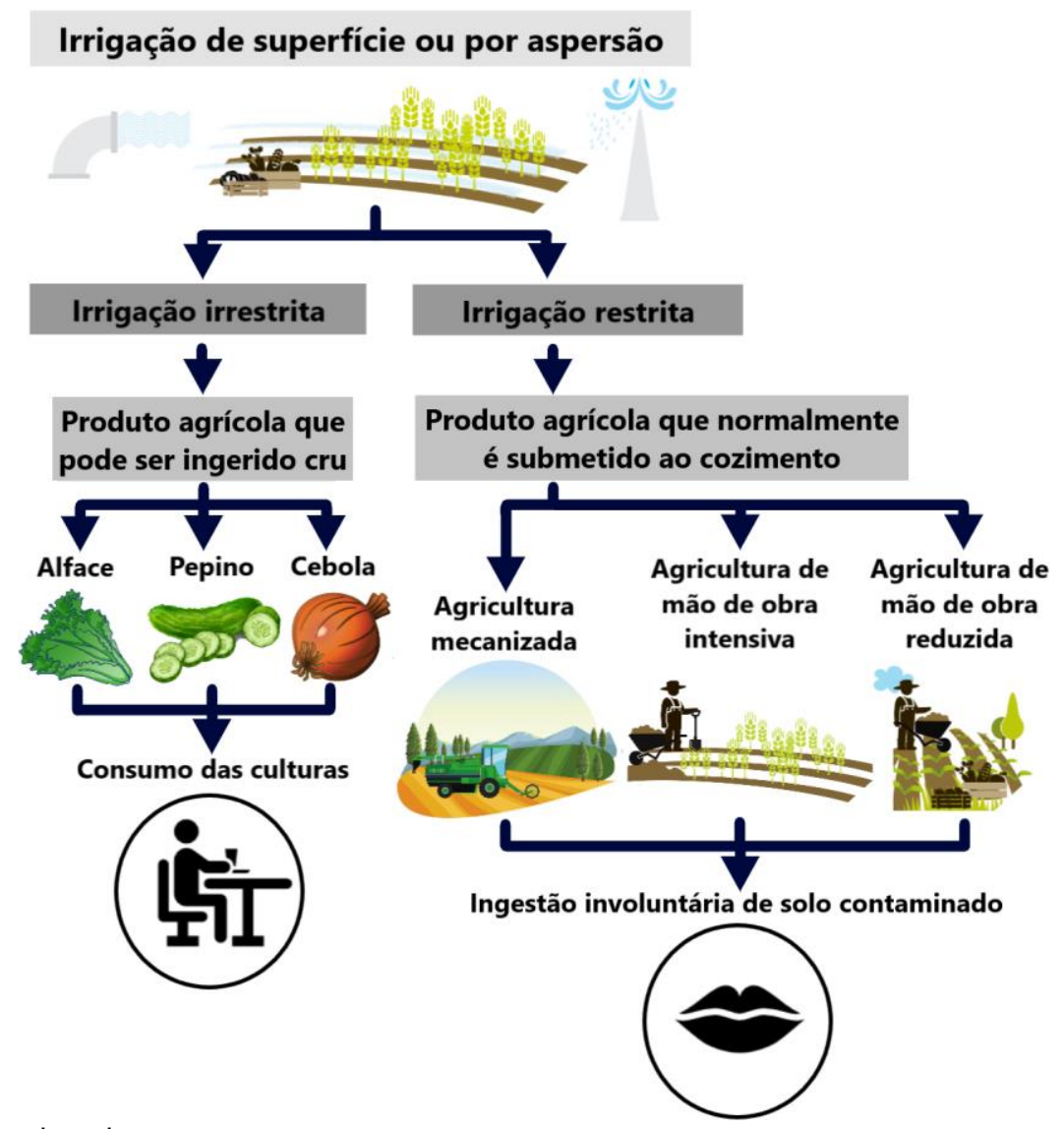

Fonte: Elaborada pelos autores.

A irrigação restrita foi definida como potencial risco à ingestão de solo contaminado por aqueles que trabalham nos campos irrigados e podem ingerir involuntariamente quantidades de solo contaminado. Não foi levado em conta o consumo das culturas propriamente, justificado pelo princípio que, na irrigação restrita, consideram-se, apenas, aqueles cultivos que não são consumidos crus (WHO, 2006a). A partir disso, foram determinados três subcenários: agricultura mecanizada, agricultura com mão de obra intensiva e agricultura com mão de obra reduzida.

$\mathrm{Na}$ irrigação irrestrita, foi definido como potencial risco o "consumo de culturas", já que tal prática envolve o consumo de culturas cruas. Assim, para representar a variedade de culturas que são consumidas cruas, foram definidos três subcenários: "Alface" (representando os cultivos em que são consumidas as folhas e que, no desenvolvimento desse cultivo, as folhas ficam próximas ao solo), "cebola (representando os 
cultivos que, em seu desenvolvimento, ficam internos a terra) e, por fim, o "pepino" (representando os cultivos que, em seu desenvolvimento, ficam externos a terra).

Em função dos inúmeros tipos de patógenos presentes nos esgotos domésticos, neste estudo, foram definidos três indicadores de patógenos que são recorrentes a associação de doenças diarréicas: uma bactéria (Campylobacter), um protozoário (Cryptosporidium) e um vírus (Rotavirus). Esses patógenos têm relevância global para a saúde pública e são conhecidos por serem transmitidos através de rotas ambientais e de origem alimentar (BASTOS et al., 2008; HAAS et al., 1999; KUNDU et al., 2018; WHO, 2006b)

A AQRM foi baseada nas taxas de patógenos estabelecidas na literatura que relacionou recorrência de $E$. coli a outros patógenos. Desta forma, a estimativa ajustada com valores de $E$. coli foi definida conforme a relação de patógenos indicadores, apresentada na Tabela 1.

Tabela 1. Relação de patógenos indicadores

\begin{tabular}{|c|c|c|}
\hline E. coli: Patógeno & Razão & Referência \\
\hline E. coli: Campylobacter & $1: 5 \times 10^{-6}$ & $\begin{array}{l}\text { Eregno et al., 2016; Mara e Sleigh, 2010; Oragui et } \\
\text { al., } 1987\end{array}$ \\
\hline E. coli: Cryptosporidium & $1: 5 \times 10^{-7}$ & $\begin{array}{c}\text { Eregno et al., 2016; Grimason et al., 1993; Mara et } \\
\text { al., 2007; Robertson et al., } 2006\end{array}$ \\
\hline E. coli: Rotavirus & $1: 5 \times 10^{-6}$ & $\begin{array}{c}\text { Bastos et al., 2008; Grimason et al., 1993; Mara e } \\
\text { Sleigh, 2010; WHO, 2016a }\end{array}$ \\
\hline
\end{tabular}

\subsubsection{Avaliação da exposição}

A avaliação da exposição determina a magnitude e a frequência da exposição a cada patógeno de referência, através das vias de exposição identificadas e eventos perigosos definidos durante a formulação do problema (WHO, 2016a). Os valores de frequência de exposição para as rotas de exposição estão descritos na Tabela 2.

Tabela 2. Parâmetros associados à dose de exposição

\begin{tabular}{|c|c|c|c|c|}
\hline $\begin{array}{l}\text { Rotas de } \\
\text { exposição }\end{array}$ & $\begin{array}{l}\text { Atividade }{ }^{1} \text { ou } \\
\text { culturas }^{2}\end{array}$ & Ingestão & Frequência/pessoa/ano & Referência \\
\hline \multirow{3}{*}{$\begin{array}{c}\text { Ingestão } \\
\text { involuntária de } \\
\text { solo contaminado }\end{array}$} & $\begin{array}{l}\text { Agricultura mecanizada }{ }^{1} \\
\text { (AAM) }\end{array}$ & $\begin{array}{c}0.0045 \\
g^{\mathrm{a}}\end{array}$ & 100 & $\begin{array}{l}\text { Mara et al., 2007; } \\
\text { WHO, 2006a }\end{array}$ \\
\hline & $\begin{array}{l}\text { Agricultura com mão de } \\
\text { obra intensiva }{ }^{1} \text { (AMR) }\end{array}$ & $0.045 \mathrm{~g}^{\mathrm{b}}$ & 300 & $\begin{array}{l}\text { Mara et al., 2007; } \\
\text { WHO, 2006a }\end{array}$ \\
\hline & $\begin{array}{l}\text { Agricultura com mão de } \\
\text { obra reduzida }{ }^{1}(A M R)\end{array}$ & $0.045 \mathrm{~g}^{\mathrm{b}}$ & 150 & $\begin{array}{l}\text { Mara et al., 2007; } \\
\text { WHO, 2006a }\end{array}$ \\
\hline \multirow{3}{*}{$\begin{array}{l}\text { Consumo de } \\
\text { culturas }\end{array}$} & Alface $^{2}$ & $5.4 \mathrm{~mL}^{\mathrm{c}}$ & $365^{c}$ & $\begin{array}{l}\text { Mara et al., 2007; } \\
\text { Shuval et al., 1997; } \\
\text { WHO, 2016a, 2006a }\end{array}$ \\
\hline & Cebola $^{2}$ & $1.0 \mathrm{~mL}^{\mathrm{d}}$ & $20^{d}$ & $\begin{array}{l}\text { Mara et al., 2007; } \\
\text { WHO, 2006a }\end{array}$ \\
\hline & Pepino $^{2}$ & $0.4 \mathrm{~mL}^{\mathrm{e}}$ & $140^{\mathrm{e}}$ & WHO, 2016 \\
\hline
\end{tabular}

${ }^{1}$ Cenários considerados para irrigação restrita (ou seja, irrigação de todas as culturas, exceto vegetais que podem ser ingeridos crus).

${ }^{2}$ Cenários considerados para irrigação irrestrita (Culturas que normalmente são ingeridas cruas).

a1-10 $\mathrm{mg}$ de solo ingerido pessoa/dia, durante 100 dias por ano

b10-100 mg de solo ingerido pessoa/dia, durante 300 ou 150 dias por ano.

${ }^{c} 100 \mathrm{~g}$ de folhas de alface consumidas por pessoa a cada 2 dias, e $100 \mathrm{~g}$ de folhas de alface retêm $10.8 \mathrm{~mL}$ de água (Imediatamente após a rega, considerando a pior das hipóteses).

${ }^{\mathrm{d}} 100 \mathrm{~g}$ de cebola consumida por pessoa/semana, durante cinco meses, e $100 \mathrm{~g}$ de cebola retêm $1.0 \mathrm{~mL}$ de água (Imediatamente após a rega, considerando a pior das hipóteses).

e $100 \mathrm{~g}$ de pepino consumido em 140 dias do ano, e $100 \mathrm{~g}$ de pepino retêm 0,4 $\mathrm{mL}$ de água (Imediatamente após a rega, considerando a pior das hipóteses). 
2.3.1. Avaliação dos efeitos à saúde

$\mathrm{Na}$ avaliação dos efeitos à saúde, os dados de impacto à saúde para os perigos identificados e a população específica do estudo, foram compilados, considerando a aplicação de modelo de dose-resposta para cada patógeno de referência determinado, que estão representados na Tabela 3, sendo o elo crítico entre a exposição ao patógeno e resultados estimados de saúde (infecção ou doença) (WHO, 2016a).

Tabela 3. Dose-resposta para organismos de referência

\begin{tabular}{|c|c|c|c|c|}
\hline Patógenos & Distribuição & Modelo & Parâmetros & Referências \\
\hline Campylobacter & Beta-poisson & 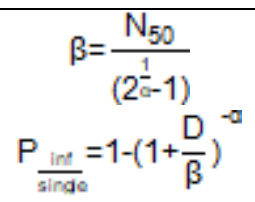 & $\begin{array}{c}\alpha=0.145 \\
\beta=7.58 \\
N_{50}=896\end{array}$ & Medema et al., 1996 \\
\hline Cryptosporidium & Exponencial & 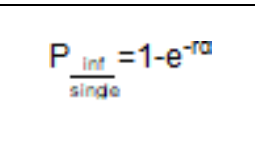 & $r=0.0042$ & $\begin{array}{c}\text { Haas et al., 1996; Masago et al., } \\
\text { 2002; Medema et al., 2003; Teunis } \\
\text { et al., } 1997\end{array}$ \\
\hline Rotavirus & Beta-poisson & $\begin{array}{c}\beta=\frac{N_{50}}{\left(2 \frac{1}{2}-1\right)} \\
P_{\frac{\text { and }}{\text { and }}}=1-\left(1+\frac{D}{\beta}\right)^{-a}\end{array}$ & $\begin{array}{c}\alpha=0.2531 \\
\beta=0.4265 \\
N_{50}=6.7\end{array}$ & Haas et al., 1999 \\
\hline
\end{tabular}

Onde,

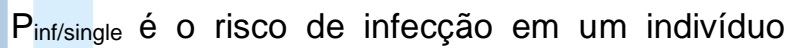
exposto após a uma única dose de patógeno $D$ $\mathrm{N}_{50}$ é a dose infecciosa mediana $\alpha$ e $\beta$ são constantes de infecciosidade dos agentes patogênicos, sendo específico para cada microrganismo

$$
\mathrm{P}_{\frac{\text { inf }}{\text { pers }}}=1-(1
$$

Onde,

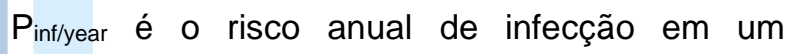
indivíduo em $n$ exposições por ano à dose única de patógeno $D$

n é o número de exposições em um determinado ano, assumido na Tabela 2

$$
P_{\text {inil }}=P_{\text {ind }}
$$

Onde,

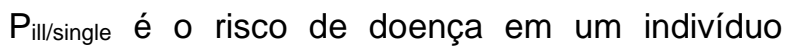
exposto a uma única dose de patógeno

Pillness/inf é a probabilidade de doença causada pela infecção, conforme representa na Tabela 4

$$
P_{\text {要 }}=1 \text { - }
$$

Onde,

Pill/year é o risco anual de doença causada por infecção

n é o número de exposições em um determinado ano, assumido na Tabela 2

Visto que nem todos os indivíduos infectados desenvolverão sintomas ao ingerir uma dose baseada em infecção modelo de resposta, pode ser necessário estimar a probabilidade de doença após a infecção (WHO, 2017, 2016a, 2006a). A probabilidade de doença causada pela infecção está detalhada na Tabela 4.

Tabela 4. Probabilidade de doença causada pela infecção e perda de DALY por caso de doença

\begin{tabular}{cccc}
\hline Patógenos & Pillness/inf & $\begin{array}{c}\text { Perda de DALY por caso de } \\
\text { doença (DB) }\end{array}$ & Referências \\
\hline Campylobacter & 0.70 & 0.0046 & Machdar et al., 2013; WHO, 2017 \\
Cryptosporidium & 0.3 & 0.0015 & Mara, 2008; WHO, 2006b \\
Rotavirus & $0.05^{\mathrm{a}}$ & 0.0140 & Mara, 2008 \\
\hline
\end{tabular}

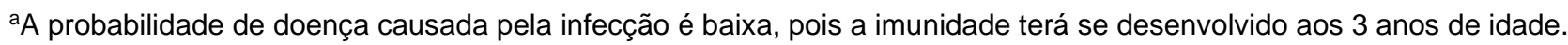


O cálculo do ano de vida ajustado por incapacidade (DALY) é definido a partir da Equação 4.

$$
\text { DALY }=\frac{\text { Pill }}{\text { year }} \times D B
$$

Onde, DB é perda de DALY por caso de doença, tendo seus valores respectivos para cada patógeno e estão representados na Tabela 4.

\subsubsection{Caracterização da avaliação quantitativa de risco microbiológico}

As avaliações de exposição e efeitos sobre a saúde são combinadas e os cálculos são realizados para quantificar e caracterizar o risco (WHO, 2016a), sendo que a modelagem de risco foi desenvolvida utilizando o software Microsoft Excel 2020. O cálculo da dose de exposição média à patógenos por evento foi quantificada conforme a Equação 5.

$$
\text { Dose de exposição }(\mathrm{D})=\mathrm{Cxq}
$$

Onde,

D é a dose de exposição (organismo)

C é a concentração de patógenos no efluente aplicado (Organismo $\mathrm{mL}^{-1}$ )

q é quantidade ingerida por evento ou atividade ( $\mathrm{mL}$ ou $\mathrm{g}$ ).

A partir de duas (2) rotas de exposição utilizadas como base, foi possível subdividir em atividades distintas, sendo elas AAM, AMI e AMR, conforme descreve a Tabela 2.

Foram adotadas reduções de patógenos durante o período de colheita e consumo do cultivo, tendo sido empregada a redução de três (3) casas logarítmicas para Campylobacter e Rotavirus, e uma (1) casa logarítmica para Cryptosporidium (DAWSON et al., 2005; MARA et al., 2007; SHUVAL et al., 1997).

A curva de dose-resposta aproximada de uma distribuição Beta-poisson e Exponencial foi derivada para os patógenos estudados com base em dados de surtos e estudos epidemiológicos, documentados em diretrizes da OMS (WHO, 2016a).

\section{RESULTADOS E DISCUSSÃO}

3.1. Desempenho dos arranjos de tratamento de esgoto doméstico
Os diferentes arranjos de tratamento de esgoto doméstico desempenharam em média resultados próximos, em que o WC-FV H com efluente proveniente do TS apresentou remoção média de 2,28 log de E. Coli, o WC-FV T com efluente do TS e de lagoas de estabilização obteve remoção de 2,24 log de E.Coli, e o conjunto de lagoas de estabilização, também tratando efluente de TS, obteve remoções médias de 2,54 log. Tais resultados estão demonstrados na Figura 3.

Os resultados foram inferiores aos valores preconizados por von Sperling (2007) como eficiência típica, a qual os WCs removeriam 3 a 4 log de coliformes termotolerantes, e as lagoas de estabilização (Lagoa Anaeróbia + Lagoa Facultativa + Lagoa de Maturação) removeriam 3 a $5 \mathrm{log}$ de coliformes termotolerantes (considerando que E. coli é $95 \%$ de coliformes termotolerantes). Contudo, Molleda et al. (2008), em estudo com WCs, obtiveram no verão remoções de 1,32 log de $E$. coli, enquanto Espinosa et al. (2016), avaliando lagoas de estabilização em grande escala no Brasil e nos EUA, encontraram remoções média de 2,2 log $E$. coli.

$\mathrm{O}$ arranjo TS + LA + LF + LM + WC-FV T (Figura $3-C$ ) não foi eficiente como refere a literatura, demonstrando um desempenho abaixo do reportado para lagoas de estabilização, e inferior ao seu potencial. Contudo, o WC-FV T desempenhou resultados condizentes com os reportados por outros autores, como Santos et al. (2020), que alcançaram remoções médias de 2,3 log para E. coli em WC-FV, e Winward et al. (2008) que auferiram remoções médias de 2,8 log para E. coli.

A concentração do efluente final dos arranjos atenderam somente as exigências da qualidade de água menor que 5 logs de E. coli. $100 \mathrm{~mL}^{-1}$, podendo ser utilizada em irrigação por gotejamento, cultivos de porte alto e na agricultura mecanizada (WHO, 2006b).

A US EPA (2012) determina a não detecção de coliformes termotolerantes para a irrigação de culturas alimentares destinadas ao consumo humano cruas, ou em culturas que serão devidamente processadas antes do consumo humano e irrigação de pastagens, cuja exigência é de 200 coliformes termotolerantes $100 \mathrm{~mL}^{-1}$. Nessas condições, nenhum arranjo atende essa qualidade microbiológica. 
Figura 3. Concentrações em $\log _{10}$ após cada tratamento para os três cenários (A, $B$ e $\left.C\right)$.

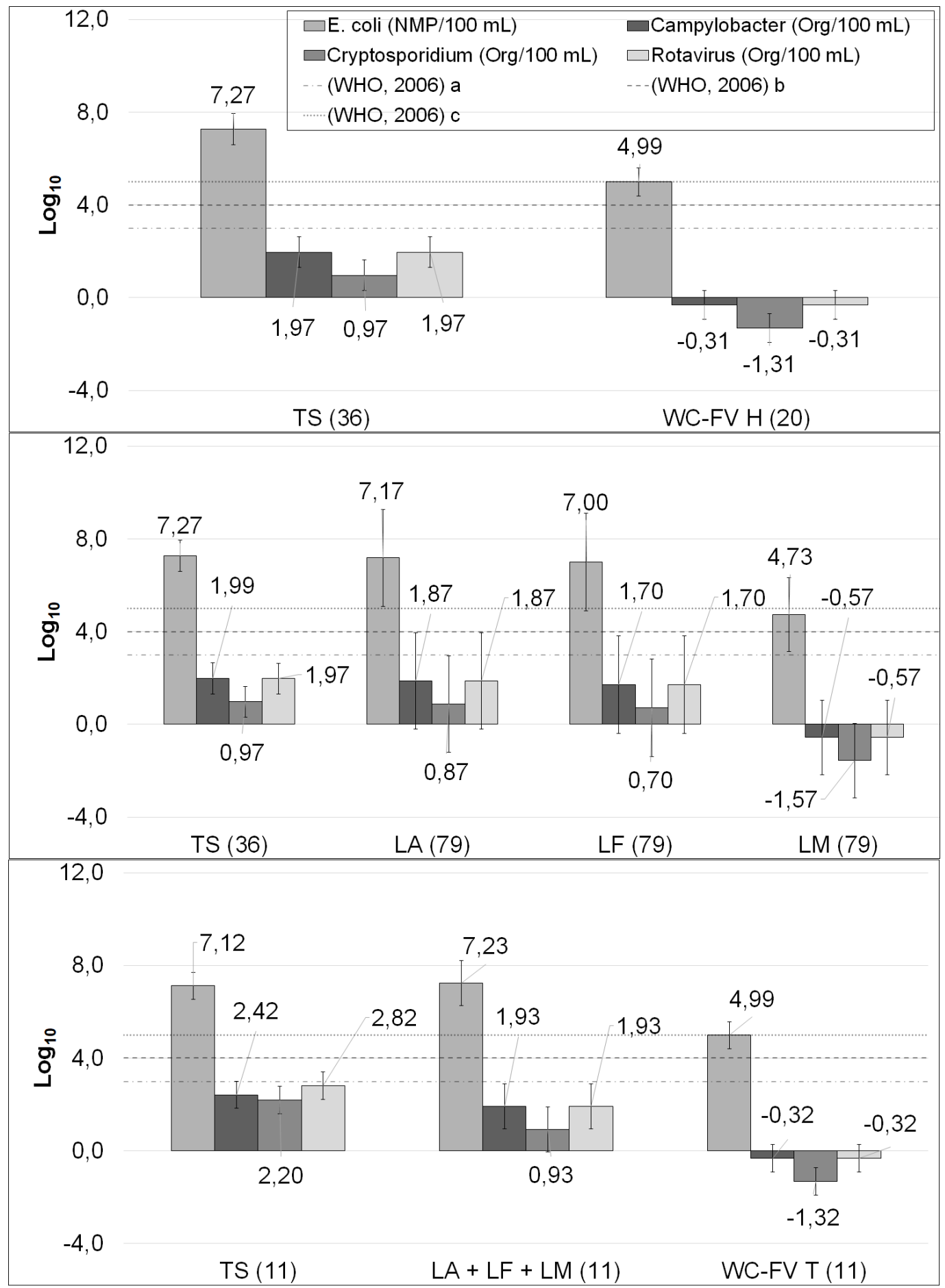

(A) TS - Tanque Séptico + WC-FVH - Wetland Construído de Fluxo Vertical Plantado com Heliconia; (B) TS - Tanque Séptico; LA - Lagoa Anaeróbia; LF - Lagoa Facultativa; LM - Lagoa de Maturação; (C) TS Tanque Séptico; LA - Lagoa Anaeróbia; LF - Lagoa Facultativa; LM - Lagoa de Maturação; WC-FV T Wetland Construído de Fluxo Vertical Plantado com Solanumly copersicum var. cerasiforme.

(Número de análises realizadas).

a Qualidade da água em 3 log E. coli. $100 \mathrm{~mL}^{-1}$ ou $100 \mathrm{~g}$ de solo-1, para irrigação irrestrita em cultivos de raízes.

${ }^{\text {b }}$ Qualidade da água em $4 \log \mathrm{E}$. coli.100 $\mathrm{mL}^{-1}$ ou $100 \mathrm{~g}$ de solo $^{-1}$, para irrigação irrestrita em cultivos de folhas ou na irrigação restrita com agricultura de mão de obra intensiva e de alto contato.

${ }^{c}$ Qualidade da água em $5 \log \mathrm{E}$. coli.100 $\mathrm{mL}^{-1}$ ou $100 \mathrm{~g}$ de solo-1, para irrigação irrestrita em irrigação porgotejamento e cultivos de porte alto ou na irrigação restrita com agricultura mecanizada 
3.2. Avaliação Quantitativa de Riscos Microbiológicos à saúde humana

A AQRM do sistema de tratamento TS + WC-FV H (Figura 4) atende o DALY pppy de 10-6 $\mathrm{e}$, consequentemente, $\mathrm{O}$ atendimento dos riscos de infecção pppy ( $P_{\text {inffyear }}$ e dos riscos de doença pppy ( $\mathrm{P}_{\text {ill/year}}$ ) das atividades de agricultura mecanizada e cultivos de cebola e pepino. Todavia, a configuração apresentou 0 não atendimento do cultivo de alface e da agricultura com mão de obra intensiva, que estão relacionados à agricultura de forma manual com alto contato.

\section{Figura 4. Avaliação quantitativa dos riscos microbiológicos do sistema de tratamento TS + WC-FV expressa em anos de vida ajustado por incapacidade por pessoa por ano (DALY pppy).}

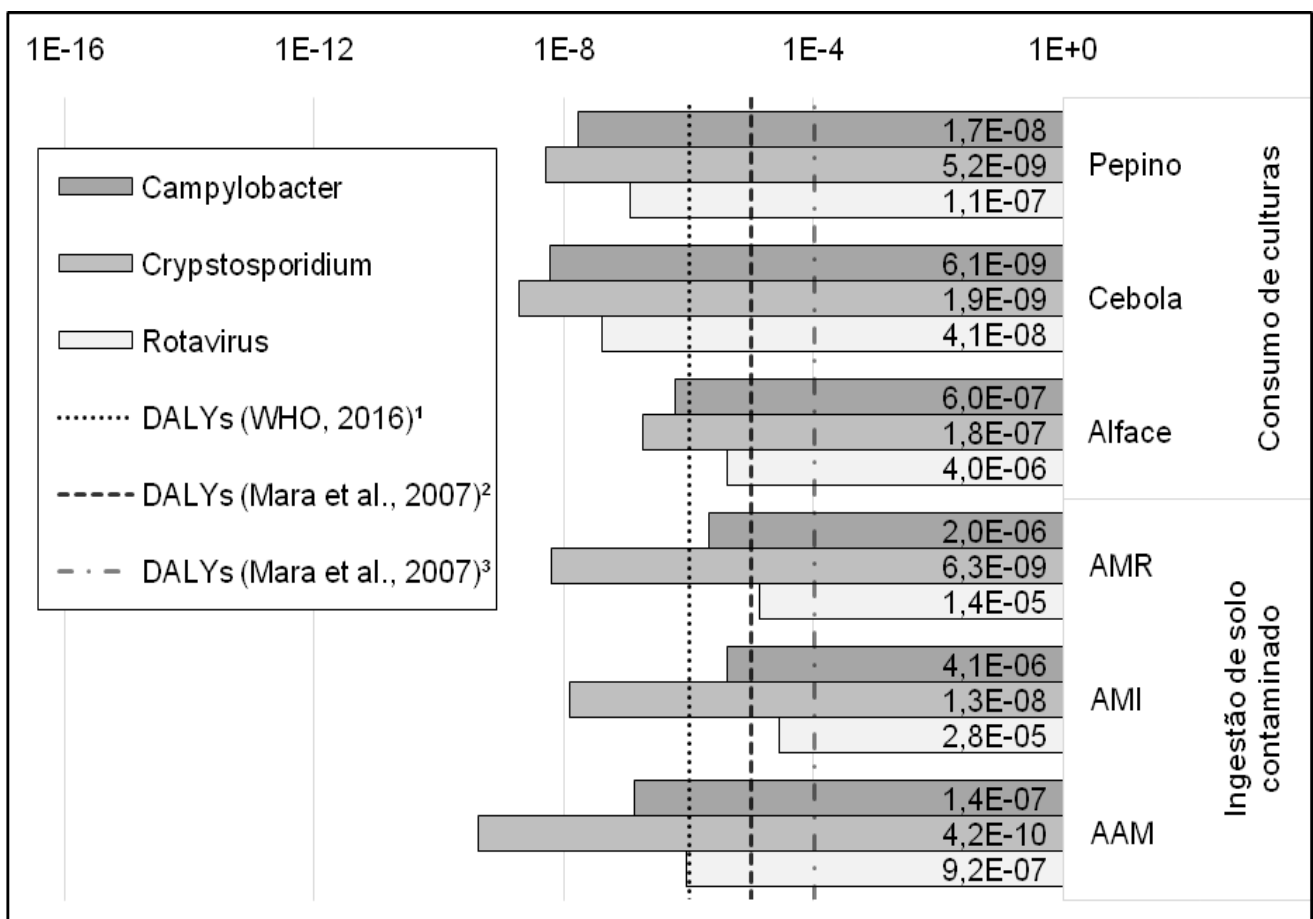

AAM - Agricultura mecanizada; AMI - Agricultura com mão de obra intensiva; AMR - Agricultura com mão de obra reduzida.

${ }^{1}$ DALYs pppy $10^{-6}$. ${ }^{2}$ DALYs pppy $10^{-5}$. ${ }^{3}$ DALYs pppy $10^{-4}$.

Estes resultados de DALYs pppy para o cultivo de cebola mostram-se divergentes aos da Figura 3, em que os resultados de concentrações de E.coli não apresentavam em conformidade para cultivo de culturas de raízes, que requer uma concentração menor que $10^{-3}$.

$O$ arranjo TS + LA + LF + LM tem seus resultados demonstrados na Figura 5 e se apresentam similares aos do arranjo TS + WC-FV $\mathrm{H}$, os quais atenderam os valores toleráveis de DALYs pppy e, consequentemente, os valores de

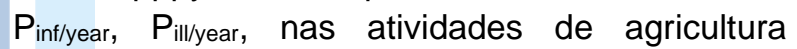
mecanizada e cultivos de cebola e pepino, mas não atendeu para o cultivo de alface.

Bastos et al. (2008), em estudo de AQRM realizado no Brasil, confirmam que as lagoas de estabilização podem, de fato, conseguir efluentes de alta qualidade e adequados para irrigação. Os autores utilizaram um sistema de tratamento com reator anaeróbio (UASB) seguido por uma série de três lagoas de polimento (maturação), alcançando uma qualidade de efluente com $6,7 \times 10^{1}$ E. coli.100 $\mathrm{mL}^{-1}$. Apesar da baixa concentração de $E$. coli, os cálculos realizados no estudo foram com o intuito de verificar se as concentrações de E. coli para reúso na agricultura atenderiam o cenário brasileiro, seguindo as recomendações da WHO (2006b). Utilizando concentrações de E. coli $10^{3}-10^{4}$ para alface e $10^{4}-10^{5}$ para pimenta verde e couve, e definindo um consumo diário para pessoas de baixa renda de $0,19 \mathrm{~g}$ de alface, $0,18 \mathrm{~g}$ de pimenta verde $\mathrm{e}$ 
$0,04 \mathrm{~g}$ de couve e, para alta renda, $1,1 \mathrm{~g}$ de alface, $0,98 \mathrm{~g}$ de pimenta verde e $0,20 \mathrm{~g}$ de couve, os cálculos demonstraram que a irrigação com efluentes estavam em conformidade com as diretrizes da OMS para irrigação irrestrita, com cultivos aceitáveis para consumo, tanto para o cenário de baixa renda como de alta renda. Entretanto, os autores não consideraram uma redução de patógenos entre a colheita e o consumo, sendo que a OMS em suas estimativas leva em consideração uma redução de 1 - 3 log de E. coli.

Figura 5. Avaliação quantitativa dos riscos microbiológicos do sistema de tratamento Tanque Séptico + Lagoa Anaeróbia + Lagoa Facultativa + Lagoa de Maturação, expressa em anos de vida ajustado por incapacidade por pessoa por ano (DALYspppy).

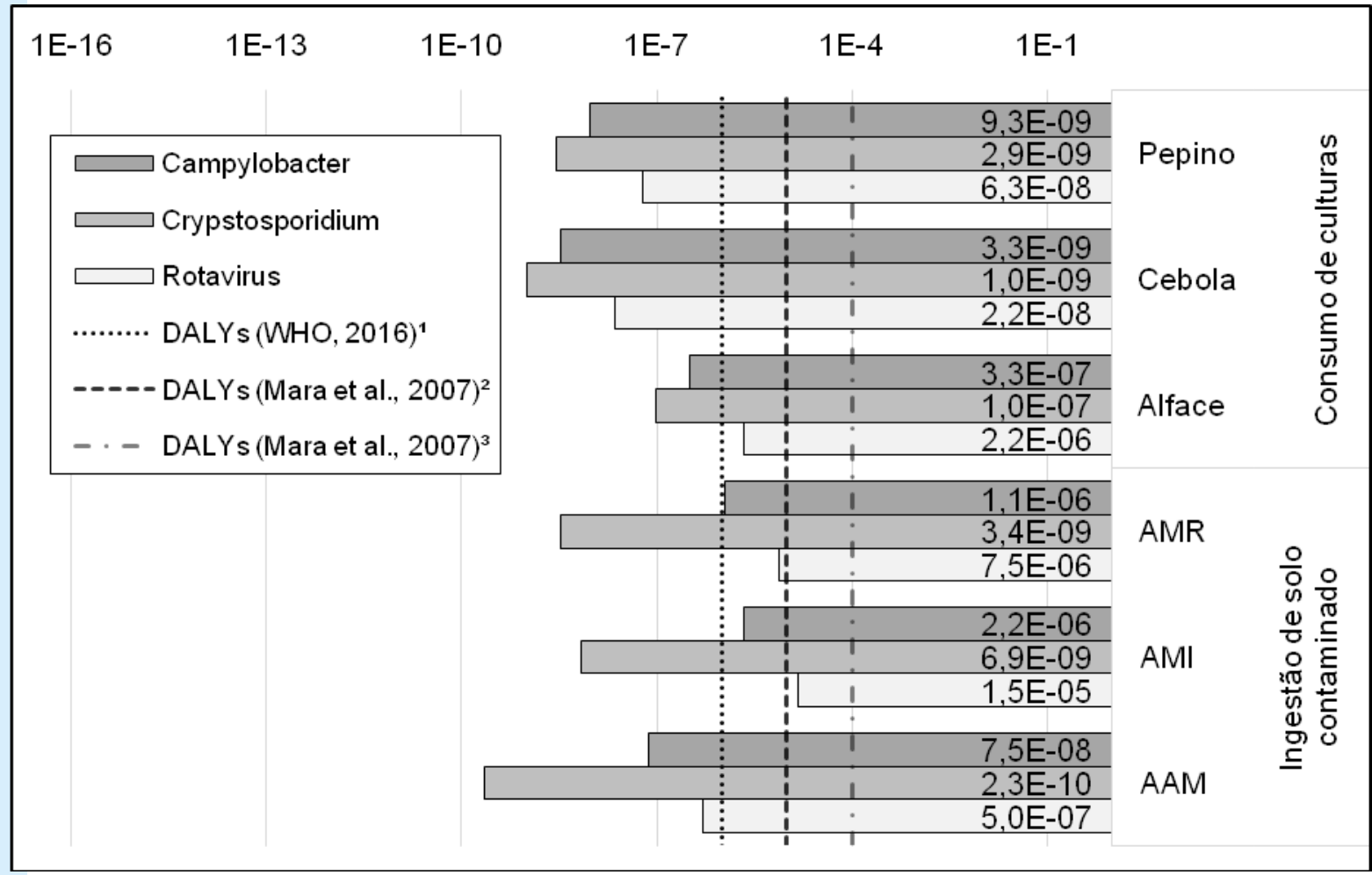

AAM - Agricultura mecanizada; AMI - Agricultura com mão de obra intensiva; AMR - Agricultura com mão de obra reduzida.

${ }^{1}$ DALYs pppy $10^{-6}$.

${ }^{2}$ DALYs pppy $10^{-5}$.

${ }^{3}$ DALYs pppy $10^{-4}$.

Fonte: Os Autores.

Na Figura 6, são apresentados os resultados obtidos da AQRM para o arranjo TS + LA + LF $+\mathrm{LM}+$ WC-FV T, que indicam o atendimento dos valores toleráveis de DALYs pppy para as atividades de agricultura mecanizada e cultivos de cebola e pepino, e o não atendimento para o cultivo de alface. Contudo, esses valores não representam 0 potencial desse arranjo de tratamento, cujas lagoas de estabilização não apresentaram eficiência típica na remoção de patógenos, conforme Figura 3. Sabe-se, no entanto, que muitas vezes os sistemas operam com sobrecarga ou com operação e manutenção inadequadas, o que diminui a eficiência de remoção de indicadores patogênicos. Sendo assim, estudos que revelam remoções abaixo do esperado são necessários para verificar o risco existente quando o sistema não está operando adequadamente.

Caso as lagoas de estabilização estivessem operando em sua eficiência típica, considerando uma remoção de 3 - 5 log de E. coli, conforme relata von Sperling (2007), mas, também, o WCFV T apresentasse uma remoção de 2,3 - 2,8 log de E. coli, de acordo com que Santos et al. (2020) e Winward et al. (2008) obtiveram, ou, até 
mesmo, com o valor de remoção de 2,24 log para E. coli, como o presente estudo evidenciou, 0 arranjo TS + LA + LF + LM + WC-FV T, de fato, atenderia o DALYs pppy de $10^{-6}$ para 0 cultivo de alface e agricultura com mão de obra intensiva.

Em um estudo semelhante de AQRM, Gonçalves et al. (2020) empregaram WC-FV em escala residencial para tratamento de água cinza (parte do esgoto doméstico, sem o componente da bacia sanitária), como pós-tratamento de filtro anaeróbio. Demonstraram dificuldades em obter qualidade satisfatória de $<10^{-4}$ pppy para Rotavirus, sendo indicados valores de 5,45.10-2 pppy para descarga sanitária e $3,04.10^{-2}$ pppy para irrigação de jardim, enquanto para Cryptosporidium spp., os valores encontrados mostraram-se satisfatórios e, para Campylobacter spp., muito próximos do limite recomendado, indicando $1,06.10^{-4}$ pppy para irrigação de jardim e $1,91 \cdot 10^{-4}$ pppy para descarga sanitária. Contudo, as remoções de E. coli encontradas pelos autores após o tratamento do WC-VF mostraram eficiências consideradas abaixo do esperado, na ordem de 1 casa logarítmica de remoção, quando o sistema operou com taxa hidráulica superior ao recomendado.

Apesar da diferença de cenário (descarga/jardim e cultivos), pois são considerados ingestões e números de exposições específicos, é possível correlacionar a dificuldade de atendimento da qualidade satisfatória de Rotavirus, para diferentes tipos de reúso e frações do esgoto doméstico. Afinal, o presente estudo, também, somente atingiu qualidade de atendimento nos cenários de consumo de cebola e pepino para esse microrganismo patogênico.

Figura 6. Avaliação quantitativa dos riscos microbiológicos do sistema de tratamento Tanque Séptico + Lagoa Anaeróbia + Lagoa Facultativa + WC-FV expressa em anos de vida ajustado por incapacidade por pessoa por ano (DALYs pppy).

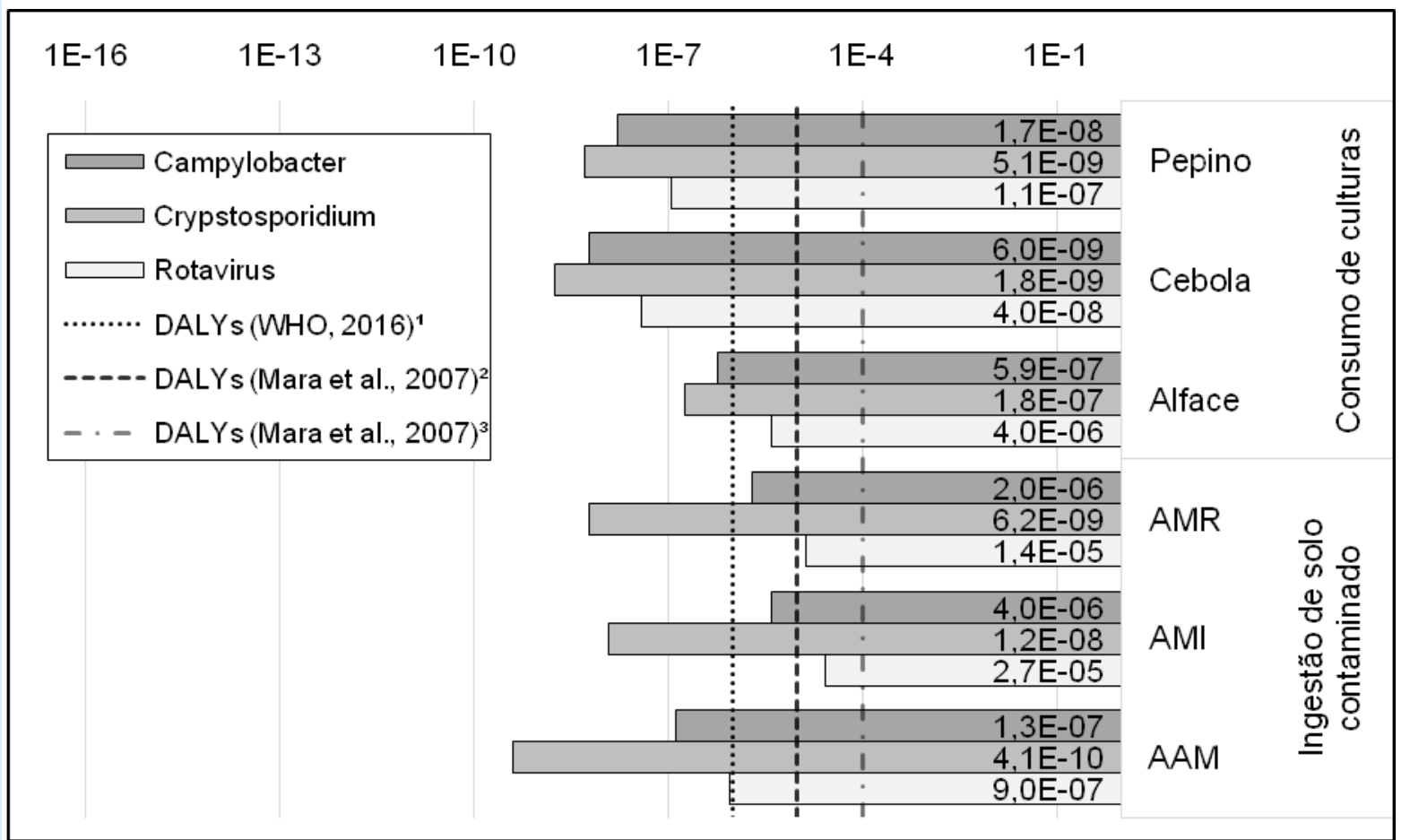

AAM - Agricultura mecanizada; AMI - Agricultura com mão de obra intensiva; AMR - Agricultura com mão de obra reduzida.

${ }^{1}$ DALYs pppy $10^{-6}$.

${ }^{2}$ DALYs pppy $10^{-5}$.

${ }^{3}$ DALYs pppy $10^{-4}$.

Fonte: Os Autores.

Mara et al. (2007) abordam o quão restritivo é o DALYs pppy de $10^{-6}$ para países em desenvolvimento, sendo que um DALY pppy tolerável de $10^{-5}$ seria mais realista, já que seria o 
suficiente para proteger a saúde do consumidor. Um requisito de DALYs menos rigoroso de $10^{-5}$ resultaria em maiores riscos toleráveis de infecção e doença, aumentando em um fator de 10 , que ainda é duas ordens de magnitude menor do que a incidência global de doença diarreica (0,1 - 1 pppy). Representaria, também, que a qualidade do efluente tratado para agricultura com mão de obra intensiva passaria de $10^{4}$ para $10^{5}$ E. coli.100 $\mathrm{mL}^{-1}$, e assim sucessivamente para as outras exigências (MARA, 2008). Dessa forma, ficaria a critério do governo local estabelecer níveis de qualidade de efluentes para reúso na agricultura, podendo ser utilizada como base a incidência local de doenças diarreicas. Caso a incidência local fosse alta (mais perto de 1 pppy do que 0,1 pppy), o DALY pppy de $10^{-5}$ atenderia com segurança. Países como Austrália e Estados Unidos apresentam incidência alta de doenças diarreicas, $\sim 0.9$ pppy e $\sim 0.8$ pppy, respectivamente, não ficando esse fato apenas restrito aos países em desenvolvimento (HALL et al., 2006; MEAD et al., 2000).

Levando em consideração o DALYs pppy $10^{-}$ 5, o arranjo TS + WC-FV H atenderia os valores toleráveis para o cultivo de alface, entretanto, ainda não seria suficiente para atender a agricultura com mão de obra intensiva ou de forma reduzida, ainda que os valores encontrados ficassem bem próximos de $10^{-5}$. Já o arranjo TS + $L A+L F+L M$ atenderia o cultivo de alface e agricultura com mão de obra reduzida, que foi considerada uma frequência de 150 dias, mas não atenderia a agricultura com mão de obra intensiva que foi considerada frequência de 300 dias.

A carga anual real de doenças diarreicas em países em desenvolvimento é estimada em $\sim 10^{-2}$ DALY pppy (MARA; SLEIGH, 2010), portanto, considerar um DALY de $10^{-6}$ em países em desenvolvimento é extremamente conservador. Desta forma, Mara (2011) recomenda que o DALYs pppy de $10^{-6}$ seja aumentado para $10^{-4}$, pois isso fornece uma margem adequada de segurança em todos os países.

Este aumento de DALY pppy seria muito promissor para o Brasil, que é um país em desenvolvimento $e$, ainda, tem as lagoas de estabilização como forma de tratamento predominante em todas as regiões do país, favorecido pelo clima propício. De acordo com Espinosa et al. (2016), existem cerca de 215 sistemas de tratamento de esgoto doméstico no Brasil que utilizam LA, LF e LM.

\section{CONCLUSÕES}

As soluções baseadas na natureza forneceram qualidade microbiológica suficiente para atender as demandas de atividades agrícolas, mesmo quando o desempenho das tecnologias foi abaixo do reportado pela literatura; - que pode ser explicado por variações nas características do efluente e aspectos operacionais e de manutenção não condizentes com o ideal.

Os wetlands construídos de fluxo vertical e as lagoas de estabilização evidenciaram uma qualidade microbiológica aceitável para atender atividades da agricultura, como a agricultura mecanizada (AAM) e cultivos de cebola e pepino, os quais apresentaram valores menores que $10^{-6}$ DALYs pppy, requerendo, por segurança, apenas uma desinfecção simples quando for mão de obra intensiva (AMI), com mão de obra reduzida (AMR), e cultivos folhosos como a alface, em que os resultados atingidos ficaram abaixo de $10^{-5} \mathrm{e}$ $10^{-4}$ DALYs pppy, respectivamente.

O sistema tanque séptico seguido por lagoas de estabilização e wetland construído de fluxo vertical demonstrou grande potencial para reúso de esgoto doméstico tratado na agricultura, pertinente à sua capacidade de remoção de indicadores de patógenos, de acordo com o que é relatado na literatura.

Embora a Avaliação Quantitativa de Risco Microbiológico ter sido realizada para cultivos que demonstram riscos altos, como a alface, cabe ressaltar que os cultivos de porte alto permitiriam - reúso de esgoto doméstico tratado com menores riscos de infecção e doenças. Além disso, outras culturas podem ser analisadas, tornando a seleção de culturas um fator dominante na implementação de projetos de reúso seguros para fins agrícolas.

\section{AGRADECIMENTOS}

Agradecimento especial ao Professor Thor Axel Stenström, professor visitante especial pelo CNPq (Processo oo 400779/2014-0), que compartilhou conosco seu vasto conhecimento e experiência em avaliação de risco microbiológico para sistemas de saneamento.

O presente trabalho foi realizado com apoio da Coordenação de Aperfeiçoamento de Pessoal de Nível Superior - Brasil (CAPES), do Conselho Nacional de Desenvolvimento Científico e Tecnológico (CNPq) e do projeto de pesquisa 
financiado pela Fundação Nacional de Saúde FUNASA (Convênio o 403/2011).

\section{REFERÊNCIAS}

ANA., 2017. Agência Nacional de Águas (Brasil). Atlas esgotos: despoluição de bacias hidrográficas/Agência Nacional de Águas, Secretaria Nacional de Saneamento Ambiental.Brasília: ANA, 88 p.ISBN: 97885-8210-050-9

ATALLA, A.; PELISSARI, C.; DE OLIVEIRA, M.; DE SOUZA PEREIRA, M.A.; CAVALHERI, P.S.; SEZERINO, P.H.; MAGALHÃES FILHO, F.J.C. Influence of earthworm presence and hydraulic loading rate on the performance of vertical flow constructed wetlands. Environ. Technol., n. 1, p. 1-9, 2020. https://doi.org/10.1080/09593330.2019.1710572

BASSANI, L.; PELISSARI, C.; DA SILVA, A.R.; SEZERINO, P.H. Feeding mode influence on treatment performance of unsaturated and partially saturated vertical flow constructed wetland. Sci. Total

Environ.,n. 754, 142400, 2021.

https://doi.org/10.1016/j.scitotenv.2020.142400

BASTOS, R.K.X.; BEVILACQUA, P.D.; SILVA, C.A.B.; SILVA, C. V. Wastewater irrigation of salad crops: Further evidence for the evaluation of the WHO guidelines. Water Sci. Technol., n. 57, p. 1213-1219, 2008. https://doi.org/10.2166/wst.2008.244

CARRANZO, I.V. Standard methods for examination of water and wastewater. Anales de Hidrología Médica, v. 5, n. 2, p. 185, jul. 2012.

DAWSON, D.J.; PAISH, A.; STAFFELL, L.M.; SEYMOUR, I.J.; APPLETON, H. Survival of viruses on fresh produce, using MS2 as a surrogate for norovirus. J. Appl. Microbiol., n. 98, p. 203-209, 2005. https://doi.org/10.1111/j.1365-2672.2004.02439.x

DECEZARO, S.T.; WOLFF, D.B.; PELISSARI, C.; RAMÍREZ, R.J.M.G.; FORMENTINI, T.A.; GOERCK, J.; RODRIGUES, L.F.; SEZERINO, P.H. Influence of hydraulic loading rate and recirculation on oxygen transfer in a vertical flow constructed wetland. Sci. Total Environ., n. 668, p. 988-995, 2019. https://doi.org/10.1016/j.scitotenv.2019.03.057

DE OLIVEIRA, M.; ATALLA, A.A.; FRIHLING, B.E.F.; CAVALHERI, P.S.; MIGLIOLO, L.; MAGALHÃES

FILHO, F.J.C. Ibuprofen and caffeine removal in vertical flow and free-floating macrophyte constructed wetlands with Heliconia rostrata and Eichornia crassipes. Chem.

Eng. J., n. 373, p. 458-467, 2019.

https://doi.org/10.1016/j.cej.2019.05.064

EREGNO, F.E.; TRYLAND, I.; TJOMSLAND, T.;
MYRMEL, M.; ROBERTSON, L.; HEISTAD, A. Quantitative microbial risk assessment combined with hydrodynamic modelling to estimate the public health risk associated with bathing after rainfall events. Sci.

Total Environ., 548-549, p. 270-279, 2016. https://doi.org/10.1016/j.scitotenv.2016.01.034

ESPINOSA, M.F.; VON SPERLING, M.; VERBYLA, M.E. Performance evaluation of 388 full-scale waste stabilization pond systems with seven different configurations. Water Sci. Technol., n. 75, p. 916-927, 2016. https://doi.org/10.2166/wst.2016.532

GONÇALVES, R.F.; DE OLIVEIRA VAZ, L.; PERES, M.; MERLO, S.S. Microbiological risk from non-potable reuse of greywater treated by anaerobic filters associated to vertical constructed wetlands. Journal of Water Process Engineering, 101751, 2020. doi:10.1016/j.jwpe.2020.101751

GRIMASON, A.M.; SMITH, H.; THITAI, W.N.; SMITH, P.G.; JACKSON, M.H.; GIRDWOOD, R.W.A. Occurrence and removal of Cryptosporidium spp. oocysts and Giardia spp. cysts in Kenyan waste stabilisation ponds. Water Sci. Technol., n. 27, p. 97104, 1993.

HAAS, C.N.; CROCKETT, C.S.; ROSE, J.B.; GERBA, C.P.; FAZIL, A.M. Assessing the risk posed by oocysts in driking water. Am. Water Work. Assoc. J., n. 88, p. 131, 1996.

; ROSE, J.B.; GERBA, C.P. Quantitative microbial risk assessment. Nova Jersey: John Wiley \& Sons, 1999.

HALL, G. V.; KIRK, M.D.; ASHBOLT, R.; STAFFORD, R.; LALOR, K.; GROUP, O.W. Frequency of infectious gastrointestinal illness in Australia, 2002: regional, seasonal and demographic variation. Epidemiol. Infect., n. 134, p. 111-118, 2006.

KADLEC, R.H.; WALLACE, S.D. Treatment wetlands. Boca Raton: CRC Press, 2008.

KUNDU, A.; ; WUERTZ, S.; SMITH, W.A. Quantitative microbial risk assessment to estimate the risk of diarrheal diseases from fresh produce consumption in India. Food Microbiol., n. 75, p. 95-102, 2018. https://doi.org/10.1016/j.fm.2018.01.017

MACHDAR, E.; VAN DER STEEN, N.P.; RASCHIDSALLY, L.; LENS, P.N.L. Application of quantitative microbial risk assessment to analyze the public health risk from poor drinking water quality in a low income area in Accra, Ghana. Sci. Total Environ., n. 449, p. 134-142, 2013.

https://doi.org/10.1016/j.scitotenv.2013.01.048

MAGALHÃES FILHO, F.J.C.M.; SOBRINHO, T.A.; 
STEFFEN, J.L.; ARIAS, C.A.; PAULO, P.L. Hydraulic and hydrological aspects of an evapotranspirationconstructed wetland combined system for household greywater treatment. J. Environ. Sci. Heal. - Part A Toxic/Hazardous Subst. Environ. Eng., n. 53, p. 493500, 2018.

https://doi.org/10.1080/10934529.2017.1422954

MARA, D. Water and wastewater-related disease and infection risks: What is an appropriate value for the maximum tolerable additional burden of disease ? J. Water Health, v. 9, n. 2, p. 217-224, 2011.

; SLEIGH, A. Estimation of norovirus infection risks to consumers of wastewater-irrigated food crops eaten raw. Water Heal., n. 8, p. 39-43, 2010. https://doi.org/10.2166.2009.140

A numerical guide to volume 2 of the Guidelines and practical advice on how to transpose them into national standards. WHO, FAO, IDRC, IWWI. 2008.

; SLEIGH, P.A.; BLUMENTHAL, U.J.; CARR, R.M. Health risks in wastewater irrigation: Comparing estimates from quantitative microbial risk analyses and epidemiological studies. J. Water Health, n. 5, p. 3950, 2007. https://doi.org/10.2166/wh.2006.055

MASAGO, Y.; KATAYAMA, H.; HASHIMOTO, A.; HIRATA, T.; OHGAKI, S. Assessment of risk of infection due to Cryptosporidium parvum in drinking water water. Water Sci. Technol., n. 46, p. 319-324, 2002. https://doi.org/10.2166/wst.2002.0756

MATEO-SAGASTA, J.; RASCHID-SALLY, L.; THEBO, A. Global wastewater and sludge production, treatment and use. In: DRECHSEL, P.; QADIR, M.; WICHELNS, D. (Eds.). Wastewater: economic asset in an urbanizing world. Dordrecht, Netherlands: Springer, 2015. p. $15-38$.

MAZUCATO, V.S.H.; SANTOS, V.B. DOS;

CAVALHERI, P.S.; MAGALHÃES FILHO, F.J.C.

Comportamento de wetland construído de fluxo vertical com fundo parcialmente saturado na remoção de matéria orgânica nitrogenada e fósforo. Brazilian J.

Dev., n. 6, p. 56506-56520, 2020.

https://doi.org/10.34117/bjdv6n8-168

MCBRIDE, G.B.; STOTT, R.; MILLER, W.; BAMBIC, D.; WUERTZ, S. Discharge-based AQRM for estimation of public health risks from exposure to stormwater-borne pathogens in recreational waters in the United States. Water Res., n. 47, p. 5282-5297, 2013. https://doi.org/10.1016/j.watres.2013.06.001

MEAD, P.S.; SLUTSKER, L.; DIETZ, V.; MCCAIG, L.F. Food-related illness and death in the United States. J.

Environ. Health, n. 62, p. 9, 2000.
MEDEMA, G.J.; HOOGENBOEZEM, W.; VAN DER VEER, A.J.; KETELAARS, H.A.M.; HIJNEN, W.A.M.; NOBEL, P.J. Quantitative risk assessment of Cryptosporidium in surface water treatment. Water Sci. Technol., n. 47, p. 241-247, 2003. https://doi.org/10.2166/wst.2003.0202

MOLLEDA, P.; BLANCO, I.; ANSOLA, G.; DE LUIS, E. Removal of wastewater pathogen indicators in a constructed wetland in Leon, Spain. Ecol. Eng., n. 33, p. 252-257, 2008.

https://doi.org/https://doi.org/10.1016/j.ecoleng.2008.05. 001

ORAGUI, J.I.; CURTIS, T.P.; SILVA, S.A.; MARA, D.D. The removal of excreted bacteria and viruses in deep waste stabilization ponds in Northeast Brazil. Water Sci. Technol., n. 19, p. 569-573, 1987. https://doi.org/10.2166/wst.1987.0236

PAVIONE,D. M. S.; BASTOS,R. K. X.; BEVILACQUA, $P$. D. Quantitative microbial risk assessment applied to irrigation of salad crops with waste stabilization pond effluents. Water Sci Technol., v. 67 n. 6, p. 1208-1215, mar. 2013. doi: https://doi.org/10.2166/wst.2013.674

ROBERTSON, L.J.; HERMANSEN, L.; GJERDE, B.K. Occurrence of Cryptosporidium Oocysts and Giardia Cysts in Sewage in Norway. Appl Environ Microbiol., n. 72, p. 5297-5303, 2006.

https://doi.org/10.1128/AEM.00464-06

SANTOS, V.B.; MACHADO, B.S.; ATALLA, A.; CAVALHERI, P.S.; MAGALHÃES FILHO, F.J.C. Microbiological evaluation of constructed wetlands and solar disinfection in wastewater treatment and reuse. $\mathbf{J}$. Water Health, v. 18 n. 6, p. 1146-1153, 2020. https://doi.org/10.2166/wh.2020.301

SHUVAL, H.; LAMPERT, Y.; FATTAL, B. Development of a risk assessment approach for evaluating wastewater reuse standards for agriculture. Water Sci. Technol., n. 35, 15-20, 1997.

https://doi.org/https://doi.org/10.1016/S02731223(97)00228-X

TEUNIS, P.F.M.; MEDEMA, G.J.; KRUIDENIER, L.; HAVELAAR, A.H. Assessment of the risk of infection by Cryptosporidium or Giardia in drinking water from a surface water source. Water Res., n 31, p. 1333-1346, 1997. https://doi.org/10.1016/S0043-1354(96)00387-9 ; OGDEN, I.D.; STRACHAN, N.J.C. Hierarchical dose response of E. coli O157:H7 from human outbreaks incorporating heterogeneity in exposure. Epidemiol. Infect., n. 136, p. 761-770, 2008. https://doi.org/10.1017/S0950268807008771

US EPA. Guidelines for water reuse. Special 
Restricted Crop Area in Mendoza, Argentina, 2012

VON SPERLING, M. Wastewater characteristics, treatment and disposal. IWA, 2007.

Introdução à qualidade das águas e ao tratamento de esgotos. 2.ed. Belo Horizonte: DESA/UFMG, 1996.

WHO - World Health Organisation. Guidelines for Drinking-Water Quality: Incorporating the First Addendum. Geneva, Switzerland. 2017.

\section{Quantitative Microbial Risk Assessment}

Application for Water Safety Management, WHO Press. 2016.

Safe Use of Wastewater, Excreta and Greywater Guidelines. Volume 2: Wastewater Use in
Agriculture. 2006a. https://doi.org/10.1007/s13398-0140173-7.2

Safe Use of Wastewater, Excreta and Greywater Guidelines for the Safe Use of Wastewater, World Health. 2006b. https://doi.org/10.1007/s13398014-0173-7.2

Guidelines for Drinking-water Quality. 3rd Edition, 2004. https://doi.org/10.1016/S14620758(00)00006-6

WINWARD, G.P.; AVERY, L.M.; FRAZER-WILLIAMS, R.; PIDOU, M.; JEFFREY, P.; STEPHENSON, T.; JEFFERSON, B. A study of the microbial quality of grey water and an evaluation of treatment technologies for reuse. Ecol. Eng., n. 32, p. 187-197, 2008.

https://doi.org/10.1016/j.ecoleng.2007.11.001 